\title{
In Silico Approach for Phytocompound-Based Drug Designing to Fight Efflux Pump-Mediated Multidrug-Resistant Mycobacterium tuberculosis
}

\author{
Santasree Sarma Biswas ${ }^{1}$. Rene Barbie Browne ${ }^{1}$. Vedant Vikrom Borah ${ }^{1}$. \\ Jayanti Datta Roy ${ }^{1}$
}

Received: 3 November 2020 / Accepted: 22 March 2021/

Published online: 7 April 2021

(C) The Author(s), under exclusive licence to Springer Science+Business Media, LLC, part of Springer Nature 2021

\begin{abstract}
Tuberculosis (TB), caused by the bacteria Mycobacterium tuberculosis, is one of the principal causes of death in the world despite the existence of a significant number of antibiotics aimed against it. This is mainly due to the drug resistance mechanisms present in the bacterium, which leads to multidrug-resistant tuberculosis (MDR-TB). Additionally, the development of new antibiotics has become limited over the years. Although there are various drug resistance mechanisms present, efflux pumps are of utmost importance because they extrude out several dissimilar antitubercular drugs out of the cell. There are many efflux pump proteins present in Mycobacterium tuberculosis. Therefore, blocking these efflux pumps by inhibitors can raise the efficacy of the existing antibiotics and may also pave the path for the discovery and synthesis of new drugs. Plant compounds can act as a resource for the development of efflux pump inhibitors (EPIs), which may eventually replace or augment the current therapeutic options. This is mainly because plants have been traditionally used for ages for food or treatment and are considered safe with little or no side effects. Various computational tools are available which are used for the virtual screening of a large number of phytocompounds within a short span of time. This review aims to highlight the mechanism and appearance of drug resistance in Mycobacterium tuberculosis with emphasis on efflux pumps along with the significance of phytochemicals as inhibitors of these pumps and their screening strategy by computational approaches.
\end{abstract}

Keywords Multidrug-resistant tuberculosis · Efflux pumps · Efflux pump inhibitors · Phytocompounds

Santasree Sarma Biswas sarma.santasree@gmail.com

1 Department of Biosciences, Assam Don Bosco University, Tapesia Gardens, Sonapur, Assam 782102, India 


\section{Introduction}

Tuberculosis (TB) is among the oldest human diseases known. It is still one of the most perilous diseases worldwide; approximately 10 million people were infected in 2018 with an estimated 1.2 million (range: 1.1-1.3 million) fatalities among HIV-negative people and further 251,000 deaths (range: 223,000-281,000) among HIV-positive people (Global TB Report 2019). India is the world's biggest TB burden nation according to WHO with a projected occurrence of 26.9 lakh cases in the year 2019 (India TB Report 2020). The causative agent of TB is Mycobacterium tuberculosis belonging to the family Mycobacteriaceae. This bacterium, first discovered by Robert Koch in 1882, has an unusual coating of mycolic acids in the cell wall and is a small bacillus, aerobic, and non-motile, which can be stained by acid-fast stain. The generation time of Mycobacterium tuberculosis is approximately $24 \mathrm{~h}$, and most TB infections initiate in the lungs, where it is called pulmonary tuberculosis; however, it can also affect other organs of the body. In the central nervous system, tuberculosis can develop mainly in the form of meningitis. It can also develop in the digestive system and also in the skin, which is called lupus vulgaris. When it infects organs other than the lungs, it is called extrapulmonary tuberculosis. Tuberculosis, in the Indian subcontinent, in particular, is one of the major etiological causes of female tubal infertility. This form of TB is called genital tuberculosis which predominantly affects the female genital organs in the pelvis, like the uterus, cervix, ovaries, fallopian tubes, and vagina or the surrounding lymph nodes. In men, prostate glands and testes are affected. Kidneys, ureters, and urinary bladder can be affected in both sexes. It usually results from the spread of infection from the lungs. There is another category of Mycobacterium also called the non-tuberculous mycobacteria (NTM) which include all bacteria of the Mycobacterium species other than Mycobacterium tuberculosis and Mycobacterium leprae, like Mycobacterium kansaii, Mycobacterium chelonae, and Mycobacterium fortuitum that are known to be environmentally opportunistic pathogens. These are present as residents of natural waters, engineered water systems, and soils. These NTM species are also responsible for respiratory diseases other than tuberculosis in animals and humans. However, most of pulmonary tuberculosis is caused by Mycobacterium tuberculosis. Most TB infections are latent in which stage the patients do not exhibit any symptoms. Nevertheless, about $10 \%$ of latent infections progress into active disease, which if remains untreated, may be life threatening. The disease's progression and prognosis can have various outcomes, largely determined by the efficiency of the host immune system [1].

\section{Tuberculosis and Mechanism of the Development of Multidrug-Resistant Mycobacterium tuberculosis}

\section{Prognosis of the Disease}

Tuberculosis signs and symptoms include blood coughing, fever, loss of weight, pain in the chest, etc. There are four stages in the course and resolution of the ailment [1]. In stage one, Mycobacterium tuberculosis makes entry into the alveolar passages of exposed human beings where they pass through the mouth and nose and also to the bronchioli and alveoli. In stage one, within about 3 to 8 weeks after Mycobacterium tuberculosis containing contaminated aerosols are engraved in alveoli, the bacteria spread into the lymphatic system. The second 
stage lasts about 3 months. In this stage, hematogenous circulation of the bacteria to other parts of the body occurs, including the lungs. Pleurisy may occur in the third stage of the disease causing severe chest pain which may extend up to 2 years. In this stage, hematogenous distribution of bacteria from the sub-pleural to the pleural spaces of the lungs occurs. The fourth or the last stage may extend up to 3 years. During this stage, extrapulmonary lesions may grow very slowly, like in joints and bones. However, most TB-infected people do not progress to this stage. TB in adults is always almost pulmonary, involving various stages of damage to the lungs like necrosis, formation of cavity, and bleeding [2].

\section{Mechanism of Tuberculosis Infection}

Upon entry of the bacilli into the alveolar passages, these are ingested by the alveolar macrophages, which trigger the innate immune system. Neutrophils and type II pneumocytes are also involved in this stage [2,3]. Phagocytosis of the bacteria occurs in macrophages. Upon entry into the macrophage, the mycobacteria remain inside a phagosome. Then phagosomelysosome fusion occurs, and the bacteria encounter an intimidating environment which consists acidic $\mathrm{pH}$, reactive nitrogen intermediate $(\mathrm{RNI})$, reactive oxygen intermediate (ROI), enzymes in the lysosomes, and venomous peptides. Like many other bacteria which try to evade the host defense system, the Mycobacterium tuberculosis also tries to prevent phagosome-lysosome fusion. There are many theories regarding the mode of action of prevention of phagosome-lysosome fusion by mycobacteria [4]. Although the innate immune system triggers various ways to kill the mycobacteria, some bacteria evade the immune system. This results in the formation of granulomatous focal lesions, which consist of lymphocytes and giant cells that are macrophage derived. Macrophages loaded with mycobacteria are destroyed by the reaction of cellular immunity resulting in the creation of a case as the granuloma nucleus, enclosed by various cells like monocytes and lymphocytes. Even though Mycobacterium tuberculosis at this stage is assumed not to be able to multiply within this cheese-like tissue due to its harsh environment, some mycobacteria may remain inactive but viable for a very long time. It is the potency of the cellular immune response of the host which decides as to whether an infection halts at this point or progression to the later stages of the disease occurs. The term for this infection is latent or persistent TB. In healthy persons with well-organized cell-mediated immunity, the infection might be permanently halted at this stage. However, there are many factors like aging, HIV infection, malnutrition, and immunosuppressive drugs which may liquefy the center of these lesions in an unknown manner. The mycobacteria within the granuloma replicate uncontrollably. At this phase, the mycobacteria can escape the granulomas and reach into other organs of the body giving rise to extrapulmonary TB and also the lung causing pulmonary TB. At this stage, the person becomes infectious and antibiotic therapy is required for cure.

\section{Treatment of Tuberculosis and Emergence of Drug-Resistant TB}

The diagnosis and treatment for patients with tuberculosis have greatly improved over the years with the development and implementation of antitubercular medications, beginning with streptomycin in 1946 and subsequent studies that has created frontline therapies of today. The major goal of tuberculosis treatment is to kill most of the bacilli and prevent drug resistance. Generally, a drug combination regimen is used [5]. 
- First-line drugs: The most common drugs used to treat tuberculosis involve isoniazid, rifampin, ethambutol, pyrazinamide, and streptomycin, which are highly effective and less toxic.

- Second-line drugs: When the first-line drugs are ineffective, second-line drugs are used. Second-line drugs are divided into four groups.

- Group A: Fluoroquinolones: this includes levofloxacin, moxifloxacin, and gentifloxacin.

- Group B: Second-line injectable agents: this includes amikacin, capreomycin, and kanamycin.

- Group C: Other second-line drugs including ethionamide, cycloserine, linezolid, and clofamizine

- Group D: This group includes pyrazinamide, bedaquiline, delamanid, $p$-aminosalicylic acid, merapenem, and thioacetazone.

Despite the presence of a number of antibiotics, the global burden of TB remains alarmingly high. The global TB epidemic has been complicated mainly because of development of drug resistance by mycobacteria. Causes of the emergence of drug resistance might be related to both the prescriber as well as the patient. Mistakes related to prescribers include prescription of inadequate non-standard medicines, inadequate supply of drugs, or unsupervised drug administration leading to loss of drug sensitivity. Pitfalls related to patients include poor adherence to treatment regimens and discontinuation of treatment. Resistance may occur under drug pressure in a patient previously treated for drug-sensitive Mycobacterium tuberculosis, ultimately leading to the rise in the numbers of drug resistance TB cases. Such patients suffering from drug-resistant TB may become the source of the spread of drug-resistant strains of TB to other individuals leading to primary drug resistance. Such strains referred as multidrugresistant tuberculosis (MDR-TB) and of late extensively drug-resistant tuberculosis (XDR$\mathrm{TB}$ ) has become one of the main hindrance in achieving control over the spread and eradication of TB. MDR-TB is when the mycobacteria become resistant to at least two of the most powerful first-line drugs: isoniazid and rifampicin. XDR-TB occurs when the Mycobacterium tuberculosis, apart from being MDR, becomes resistant to fluoroquinolone and at least one of the three injectable second-line drugs such as amikacin, capreomycin, and kanamycin.

\section{Mechanism of Drug Resistance in Mycobacteria}

There are various mechanisms by which drug resistance in bacteria occurs. Bacterial drug resistance may be intrinsic or acquired. Intrinsic drug resistance mechanisms occur by genes specified for resistance present in the host DNA, e.g., $\beta$ lactamase gene of Gram-negative bacteria. Mechanisms of acquired drug resistance include mutations in antibiotic-targeted genes and the transfer of resistance factors present on plasmids, transposons, bacteriophages, and other mobile genetic elements via transduction, conjugation, and transformation [6]. However, horizontal gene transfer is not reported in mycobacteria because, so far, there is no strong evidence of the presence of plasmids in mycobacteria [7, 8]. Many good-quality reviews discuss the mechanisms of mycobacterial drug resistance in detail $[9,10]$. The different drug resistance mechanisms are briefly discussed below: 
Blocked Penetration of Substances One of the main causes of intrinsic resistance to most of the drugs in mycobacteria is its unusual cell wall structure. It acts as a permeation barrier for most of the antibiotics like $\beta$-lactams and tetracyclines. The mycobacterial cell wall is an extraordinary structure containing less porins and lipid bilayer of very low fluidity and irregular thickness which limits the access of lipophilic as well as hydrophilic antibiotics inside the cell. The hydrophilic drugs cross the cell wall gradually since the mycobacterial porin is incompetent and allows the access of solutes in low concentration. Lipophilic substances are believed to be hindered by the lipid bilayer, which is of bizarrely poor fluidity and peculiar thickness. However, the cell wall hurdle alone is not sufficient for production of a significant amount of resistance [11].

Inactivation or Modification of Drugs One of the most common mechanisms of acquiring resistance is by inactivation or modification of drugs. These consist of genes encoding enzymes that destroy the antimicrobial agents. Gene mutations in several loci of the mycobacterial genome is the chief cause of resistance to most of the antimicrobials [12]. An example includes the $\beta$-lactamases that destroy the antibiotics before it reaches the target. $\beta$ lactam antibodies against mycobacterium are futile. This is due to the production of a $\beta$ lactamase enzyme encoded by the blaC gene of $M$. tuberculosis that degrades these antibiotics. Isoniazid, which is a first-line antibiotic and effective against metabolically active replicating bacilli, is also inhibited by mutations in several genes like $\operatorname{ahpC}, \operatorname{kas} A, \operatorname{kat} G \operatorname{inh} A$, and $N D H$ [9]. Similarly, several other gene mutations occur, which render the mycobacteria resistant to many antibiotics like mutations in $p m c A$ gene for pyrazinamide resistance, $r p s L$, and $r r s$ in streptomycin resistance, whereas ethambutol resistance is linked to the mutation in gene $e m b B$ [9].

Inactivation of the Receptors of Drugs This is another very common mode of drug resistance in mycobacteria. Fluoroquinolones are applied in the treatment of MDR-TB as second-line antibiotics. Almost all fluoroquinolone resistance is a result of mutations in the drug targets, DNA gyrase (topoisomerase II), and topoisomerase IV, which are imperative for bacterial survival. In Mycobacterium tuberculosis, only topoisomerase II is present which consists of a tetramer consisting $\alpha$ and $\beta$ subunits. These are encoded by the genes gyrA and gyrB, which catalyze DNA supercoiling, respectively. Fluoroquinolone resistance is caused by mutations in $g y r A$ or $g y r B$. Rifampicin, which is a rifamycin derivative is also rendered ineffective by the modification of its target. Resistance to rifamycins is caused by point mutations in the rifampin-binding region of $r p o B$, which encodes RpoB, the $\beta$ subunit of RNA polymerase where rifampin binds. Therefore, rifampin cannot bind to the structurally altered $\beta$ subunit due to lack of affinity and resistance is conferred. Mycobacterium tuberculosis resistance to first-line antibiotics like rifampicin by this mechanism is widespread [10].

Efflux Pumps One of the well-studied mechanisms of drug resistance in bacteria is through efflux pumps. Efflux was first documented as a drug resistance mechanism in 1980 [13]. However, the contribution of efflux pumps in conferring clinically significant levels of drug resistance in mycobacteria was poorly understood earlier and ignored by many. However, studies have demonstrated the presence of several efflux pumps and their involvement in antibiotic resistance [14]. Approaches based on bioinformatics show a close correlation between efflux pumps and innate or acquired drug resistance in 
Mycobacterium tuberculosis [15]. In many clinically resistant isolates of Mycobacterium tuberculosis, no gene mutation was seen initially. Drug efflux was the major cause of resistance in these bacteria. Drug efflux is a mechanism where a transporter is able to extrude out multiple drugs without having any structural similarity from the cytoplasm to the exterior of the cell. These are also called multidrug (MDR) efflux pumps which extrude out structurally dissimilar compounds, including antibodies of various classes. The efflux pumps also have other roles in addition to efflux, such as pathogenicity, virulence, biofilm production, and quorum sensing [16]. Efflux pumps (EPs) not only decrease the accumulation of antibiotics inside the cells but also during this time, the bacterium gets sufficient time to adapt to the antibiotics and become resistant through mutations or alteration of antibiotic targets. Six to $18 \%$ of the mycobacterial genome encodes putative EPs [12]. Mycobacterium tuberculosis has one of the greatest numbers of probable EPs in comparison with its genome size [17, 18]. Among the various MDR mechanisms, the main focus is on efflux pumps as they contribute to MDR of Mycobacterium tuberculosis in most cases [19]. There are essentially five separate families of efflux pump proteins. They are ATP-binding cassette (ABC) superfamily efflux pumps, major facilitator superfamily (MFS) efflux pumps, resistance nodulation division (RND) family efflux pumps, small multidrug resistance (SMR) family, and multidrug and toxic compound extrusion (MATE) family efflux pumps.

\section{Types and Molecular Mechanism Of Efflux Pumps}

ABC Superfamily Efflux Pumps These are made from ABC proteins found in bacterial cytoplasmic membranes as well as eukaryotic plasma membrane and organelle membranes. These are large transmembrane proteins that transfer a wide variety of substrates like antibodies, sugars, antibiotics, toxins, lipids, and bile salts. It has 52 subfamilies. Prokaryotic ABC proteins are either importers or exporters. Eukaryotes exclusively express exporters. They pump their substrates up a concentration gradient utilizing the energy of ATP hydrolysis. ABC efflux pumps consist of 12 transmembrane alpha-helices which form four domains which include two transmembrane domains (TMDs) and two nucleotide binding domains (NBDs). TMDs differ in sequence and architecture. These variable sequences are responsible for the chemical diversity of substrates that can be translocated. Some of the efflux pumps of ABC superfamily found in mycobacteria known to cause drug resistance are Rv1217c and Rv1218c, conferring isoniazid and beta-lactam resistance [20]. Rv1456c-Rv1457c-Rv1458c, Rv2686cRv2687c-Rv2688c confer ciprofloxacin resistance and $d r r A(r v 2936)$ and $d r r B(r v 2937)$, $\operatorname{drr} C(r v 2938)$ expression confer resistance to a wide variety of antibiotics like ethambutol, rifampicin, streptomycin, and tetracycline while Rv0194 was reported to confer resistance to beta-lactam antibiotics [21-23]. Rv1747 induces isoniazid resistance, and pstB(Rv0933) induces resistance to isoniazid, rifampicin, ciprofloxacin, and ethambutol [24, 25]. $r v 2477$ overexpression has been reported in ofloxacin stress in M. tuberculosis [26]. itrA(rv1348), itrB(rv1349), Rv1272c, and Rv1273c are reported to be multidrug transporters [25]. bacA $(r v 1819 c)$ is a transporter of isoniazid and rifampicin and it also helps in vitamin $\mathrm{B}_{12}$ acquisition by the bacterium [27]. Rv3000 is also a putative efflux pump [28]. Rv1463 is an efflux pump of this family but the drugs extruded are still undetermined [29]. Rv1686c and Rv1687c are also reported to belong to this family but the drugs expelled are not yet determined [30]. 
Major Facilitator Superfamily It is present and conserved across all kingdoms of life: from bacteria to humans. This is an ancient family representing the largest secondary transporter family. This family represents $25 \%$ of all known transporters. These pumps utilize the proton motive force as a source of energy. They are single polypeptide carriers. They can be uniporters, symporters, or antiporters. These also transport various classes of substrates like inositols, metabolites of Krebs' cycle, and sugars. The transporters of this family consist of 12 or 14 alpha helical transmembrane proteins which are connected by a hydrophilic loop having both $\mathrm{NH}_{2}$ and $\mathrm{COOH}$ terminals in the cytoplasm. Bmr and Blt of Bacillus subtilis, MdfA of Escherichia coli, and LmrP of Lactobacillus lactis, NorA, and QacA of S. aureus belong to this class of efflux pumps [31]. Overexpression of NorA produces resistance to chloramphenicol and hydrophilic fluoroquninolones [31]. This confers resistance to fluoroquinolones and ethidium bromide. PmrA of $S$. pneumoniae also provides resistance to fluoroquinolones. LfrA of this family was the first MDR pump to be studied in Mycobacterium tuberculosis [32]. $\operatorname{EfpA}(r v 2846 c)$, Tap, or P55 are some other efflux pumps reported in several species of mycobacteria that are associated with resistance to several antibiotics. EfpA probably confers resistance to isoniazid. Tap or P55 are identified to confer low resistance to tetracycline and aminoglycosides [33]. In 2004, a Tap-like efflux pump, Rv1258c, was reported in multidrugresistant Mycobacterium tuberculosis, and whenpresent with rifampicin and ofloxacin, its overexpression was observed [34]. This efflux pump was also reported to be associated with second-line fluoroquinolone and aminoglycosides antibiotic resistance [35]. Rv0849 provides resistance to $\beta$-lactams [20].

Resistance Nodulation Division Family Members of this family are found mostly in Gramnegative bacteria. They play a major role in drug resistance. This protein forms a homotrimer. The structure has been studied elaborately in Acr pumps of E. coli. It consists of three components: a transporter (efflux) protein in the inner membrane (e.g., AcrB), a periplasmic accessory protein (e.g., AcrA), and an outer membrane protein channel (e.g., TolC), either termed an outer membrane protein (OMP) or outer membrane factor. It extrudes a large range of cell substrates. These are antiporters. The most common RND efflux pump, which has been studied extensively is AcrAB-TolC [36]. In the Mycobacterium tuberculosis genome, there are 12 genes that code for the RND pumps and are considered important for survival and virulence of mycobacteria [37]. MmpL3 is a very important protein of this family because it is used for the transport of mycolic acids in trehalose monophosphate form to the outer membrane or into the periplasmic space. Due to this essential role, MmpL3 is a drug target with immense interest [38]. MmpL7(rv2942) is a putative efflux pump that confers isoniazid resistance in Mycobacterium tuberculosis [39]. MmpL5(rv0676c) confers resistance to tetracycline. It has also been found that mutations occurring $r v 0678$ gene encoding MmpL5 repressor are responsible for bedaquilline and clofazimine resistance [40]. MmpS5(Rv0677c) confers resistance to tetracycline. MmpL11(rv0202c), MmpL4(rv0540c), and MmpL3(rv0206c) are also putative efflux pumps in Mycobacterium tuberculosis belonging to this family, but their exact role in drug efflux is yet to be determined [41].

Small Multidrug Resistance Family These are the smallest known transporters consisting of proteins localized in the inner membrane of primarily Gram-negative bacteria. These are alpha helix transmembrane proteins consisting of 100 to 140 amino acids. EmrE of E. coli is an extensively studied SMR pump conferring resistance to ethidium bromide and methyl viologen [42]. This pump is also present in Pseudomonas aeruginosa. Other well-studied 
examples are EbrAB of Bacillus subtilis and SsmE of Serratia mercescens. AbeS of Acinetobacter baumanii showed resistance to antimicrobials, dyes, and detergents [43]. In Mycobacterium tuberculosis, $\operatorname{Mmr}(r v 3065)$ is an efflux pump belonging to this category conferring resistance to TPP1, acriflavin, EtBr, erythromycin, safranin O, and pyranin Y [44].

Multidrug and Toxic Compound Extrusion Family The MATE (multidrug and toxic compound extrusion) family is one of the five multidrug efflux transporter families, which is most recently classified as one. A few MATE transporters have been identified so far, but a large number of MATE transporters appear to be present in various microorganisms according to information in sequence databases. A structural model suggests that the polypeptide chain spans the membrane four times as slightly amphipathic $\alpha$ helices [44]. The antiport of substances coupled with $\mathrm{Na}^{+}$was frequently stated as one of the distinctiveness of clustered MATE-type transporters. MATE-type pumps are divided into three classes based on phylogeny [45]. The first MATE-type transporter to be discovered was NorM from V. parahaemolyticus. NorM from Vibrio parahaemolyticus, NorM from Vibrio cholerae, and YdhE from E. coli belong to cluster 1. Cluster 2 comprises of eukaryotic proteins belonging to animals, plants, fungi, or yeast. Proteins analogous to DinF in E. coli are grouped in cluster 3 [46]. Activities of increased drug resistance were seen in the homologues of DinF in many bacterial species, e.g., VmrA from V. parahaemolyticus, MepA from S. aureus, and DinF from Ralstonia solanacearum. MGH78578 is another efflux pump of this family, which was characterized in K. pneumoniae [47]. However, transporters of the MATE family are not reported in mycobacteria.

Previously, in several studies, efflux pump genes have been shown to be upregulated upon exposure to drugs or implied to be overexpressed in drug-resistant strains [48]. In a study, the expression profiles of putative efflux pump genes were conducted using RT-PCR in MDR strain 1499. Transcription of genes $r v 1258 c, r v 1410 c$, and $\mathrm{r} v 1819 c$ was found to be increased upon rifampicin or isoniazid exposure [49]. Most efflux pump genes are overexpressed under drug pressure, and such overexpression of genes results in higher drug resistance. But the function of mutations in efflux pumps found in clinical isolates in increasing drug resistance is largely unknown. Several single nucleotide polymorphisms were also noticed in some efflux pump genes such as $r v 1258 c, r v 1273, r v 1217, r v 1877, r v 1250, r v 2688$, and $r v 0194$, but their exact relevance to drug resistance is yet to be elucidated [50]. A study was conducted to show the role of point mutations V219A and S292L in the gene rv1258c. Point mutations V219A and S292L in $R v 1258 c$ were shown to cause significant drug resistance to pyrazinamide (PZA), isoniazid (INH), and streptomycin (SM), although not to other drugs in Mycobacterium tuberculosis. V219A point mutation resulted in low-level resistance to drugs, whereas S292L mutation developed a higher degree of resistance. It was also shown in the S292L mutant that piperine inhibited isoniazid and pyrazinamide resistance but not in V219A mutant. S29L mutants displayed an efflux capacity for pyrazinoic acid (which is the active form of pyrazinamide) more than the wild strain [49].

\section{Phytocompounds for Mitigation of Efflux-Mediated Drug Resistance in Mycobacteria Through Computational Methodologies}

Human beings have mostly relied on nature over the ages for their essential needs which also include medicines. Plants have formed the basis of complex traditional therapeutic systems 
that have existed for millennia. Across the world, from the pre-historic times, there are various records where human beings have used plants for the development of drugs [51, 52]. In India, the uses of plants as medicine are mentioned in the Rig Veda, the oldest document. Plants have been the chief source of treatment of various ailments since thousands of years in India. Charaka Samhita, a book on the Indian traditional medicine, Ayurveda, contains information as well as evidence of many plants being for medicinal purposes. The first non-European record of tuberculosis is also found in the Vedas. The Atharva Veda mentions the use of some herbs in the management of tuberculosis. These include Piper longum, Pinus longifolia, and Sida cordifolia [53, 54]. A large number of studies are carried out throughout the world exploring the scope of medicinal plants in the treatment of tuberculosis. Several compounds from plant sources were also reported to prevent the growth of Mycobacterium tuberculosis by in silico studies [55]. A large number of plants have been mentioned in books which are used for the treatment of tuberculosis by traditional methods [56]. For the last hundreds of years, chemical compounds isolated from plants have served as basis for formulation of drugs against several diseases. This method can also be applied for tuberculosis. In India, there are several thousands of plant species that are used in the form of ethnomedicines. The knowledge about these plants is passed verbally from one generation to another. India is a land of various tribal communities, and these people are very well-informed about the usefulness of plants mainly for food and medicines. Scientific exploration of this knowledge of the tribal communities may open a new area of knowledge as these plant species have a significant potential for the development of drugs against MDR-TB. Some of plants used for the treatment of tuberculosis by a few ethnic communities of India are mentioned in Table 1:

The problem of antibiotic resistance is prevalent throughout the globe. The most common drug-resistant bacteria include carbapenem-resistant Acinetobacter baumanii, carbapenem-

Table 1 Some of the plants traditionally used for tuberculosis treatment in India

\begin{tabular}{|c|c|c|c|c|c|c|}
\hline $\begin{array}{l}\text { Sl. } \\
\text { No. }\end{array}$ & Scientific name & Family & Local name & $\begin{array}{l}\text { Place where } \\
\text { mostly used }\end{array}$ & $\begin{array}{l}\text { Parts of the } \\
\text { plant used }\end{array}$ & References \\
\hline 1. & Solanum nigrum & Solanaceae & Byako & $\begin{array}{r}\text { Arunachal } \\
\text { Pradesh }\end{array}$ & $\begin{array}{l}\text { Berries, } \\
\text { leaves, } \\
\text { shoots }\end{array}$ & {$[57]$} \\
\hline 2. & Centella asiatica & Apiaceae & $\begin{array}{l}\text { Ngyarikor, Bor } \\
\text { manimuni }\end{array}$ & $\begin{array}{c}\text { Arunachal } \\
\text { Pradesh, } \\
\text { Assam }\end{array}$ & Whole plant & {$[58,59]$} \\
\hline 3. & Musa balbisiana & Musaceae & Bhim kol & Assam & Leaves & {$[60]$} \\
\hline 4. & Alocasiafornicata & Araceae & Baibing/Dawl & Mizoram & Fruit & {$[61]$} \\
\hline 5. & Aeridis odorata & Orchidaceae & N/A & Nagaland & Leaf & [62] \\
\hline 6. & Dendrodiumnobile & Orchidaceae & N/A & Nagaland & Stem & [63] \\
\hline 7. & $\begin{array}{l}\text { Strophanthus } \\
\quad \text { wallichii }\end{array}$ & Apocynaceae & Tylle sanein & Meghalaya & Stem/root & [64] \\
\hline 8. & $\begin{array}{l}\text { Stephania } \\
\quad \text { herandifolia }\end{array}$ & Menispermaceae & Jabung & Meghalaya & Stem/root & {$[64]$} \\
\hline 9. & Curcuma caesia & Zingiberaceae & Karo hardi & Sikkim & Rhizomes & {$[65]$} \\
\hline 10. & Abies wobbiana & Pinaceae & Gobre salla & Sikkim & Leaf, gum & [66] \\
\hline 11. & $\begin{array}{l}\text { Abelmoschus } \\
\text { esculentus }\end{array}$ & Malvaceae & Muskdana & Madhya Pradesh & Leaf, root & {$[67]$} \\
\hline 12. & Ocimum basilium & Lamiaceae & Van tulsi & Chhattisgarh & Whole plant & {$[67]$} \\
\hline 13. & Basella alba & Basellaceae & Pui & West Bengal & Whole plant & [68] \\
\hline 14. & $\begin{array}{l}\text { Opuntia } \\
\quad \text { ficus-indica }\end{array}$ & Cactaceae & Cactus & West Bengal & Branch & [68] \\
\hline
\end{tabular}


resistant Pseudomonas aeruginosa, and carbapenem-resistant and extended-spectrum betalactamase (ESBL) producing Enterobacteriaceae, vancomycin-resistant Enterococcus faecium, methicillin-resistant Staphylococcus aureus, clarithromycin-resistant Helicobacter pylori, fluoroquinolone-resistant Campylobacter spp., fluoroquinolone-resistant Salmonellae and cephalosporin and fluoroquinolone-resistant Neisseria gonorrhea leading to limited the use of already existing antibiotics [69-71]. MDR and XDR-TB impose a major challenge in this field with a growing number of cases each year worldwide. It is evident that the currently available antibiotics are insufficient to control these antibiotic-resistant bacteria. This problem has also necessitated the continued search for novel antimicrobial compounds.

In this regard, plants are a main source of natural products that can be explored because of abundant metabolite content and common pathways which can be easily manipulated. Because of their cosmopolitan nature, these plants can be easily cultivated throughout the world. Although a good percentage of all pharmaceutical products present in the world are derived from plants, very few are used as antimicrobials. Plant-derived natural compounds are attracting more attention in the present age because of its potential efficacy and no side effects. Plants are a rich source of secondary metabolites such as quinones, tannins, terpenoids, alkaloids, flavonoids, and polyphenols. These compounds are used by plants as a means of protection against microorganisms, herbivores, and insects. Terpenoids are the compounds which give plants their odors; quinones and tannins are required for plant pigmentation. Many compounds, such as flavonoids are responsible for the color of the fruits. Some of the herbs and spices, which are being used by humans to season foods, could yield useful antimicrobial compounds. These plant substances are classified as phytoanticipins, or phytoalexins. Phytoanticipins are present constitutively, whereas phytoalexins are those compounds whose levels increase strongly in response to microbial attack [72]. In spite of all the advantages, bioactive compounds derived from plants are still used in small proportions as antimicrobials.

However, interest in medicinal plants has amplified over recent years. Many plant compounds have been reported, which show very little antimicrobial characteristics. It was suggested that a vast majority of plant antimicrobials that shows little antibacterial activity in vitro are regulatory compounds in plant playing an indirect role in defense against microbial infections [73]. These compounds are synthesized in response to pathogen attack and are required to protect the plant from pathogens, which might also play a role in regulatory function, which in turn indirectly increases the level of resistance of the plant. Plant extracts have the ability to increase the efficacy of antibiotics. It is observed that inhibition of drug efflux and alternative mechanisms of action could be responsible for the synergistic interactions between plant extracts and antibiotics [74].

The ability of some plant chemical compounds (called MDR inhibitors or resistance modifying agents) to modify the resistance phenotype in bacteria by working synergistically with antibiotics in vitro has been observed [74]. The search for such compounds which can be combined with antibiotics in the treatment of drug-resistant infections may be an alternative in overcoming the problem of resistance in bacteria. Crude extracts of remedial plants stand out as genuine sources of promising resistance modifying agents $[75,76]$.

The discovery and development of clinically efflux pump inhibitors (EPIs) that decrease the effectiveness of efflux pumps represents a major advance in the development of therapeutic regimens for the treatment of MDR-related conditions. This approach is termed the EPI strategy [77]. It is based on blocking the activity of the pumps, resulting in the accumulation of the antibiotic inside the bacterial cell and, thus, escalating access to its target sites. Along with this, it will lead to increased susceptibility of the bacterium, thus increasing the 
therapeutic effect of the drug at lower concentrations. The broad-spectrum efflux pump inhibitors can be used as an adjuvant with current drugs that are pump substrates that can reverse the clinically important activity of those compounds and thus may provide new dimensions to the ever-rising need for the development of new antimicrobial agents [78]. In addition, this approach may lead to the preservation and improvement of the usefulness of old and cheap antibiotics. Eventually, this could lead to the reduction of the appearance and spread of resistant mutants.

Several reviews have highlighted the importance of plant-based efflux pump inhibitors [79-81]. Several compounds of plant origin, which can act as efflux pump inhibitors of bacteria and show a significant role in antiefflux activity of drugs, have been reported. A number of pure compounds of plant origin have been isolated and reported to have resistance modifying activities in vitro. Camellia sinensis have been found to have antibacterial properties due to the presence of polyphenols like epicatechingallate, epigallocatechin gallate epicatechin, and caffeine [82]. Ethyl gallate, purified from a dried pod of tara (Caesalpinia spinosa), intensified $\beta$-lactam susceptibility in MRSA and MSSA strains [83]. The abietane diterpenes (carnosic acid, carnosol) isolated from the aerial parts of Rosmarinus officinalis shows resistance against $S$. aureus. Carnosic acid was shown to inhibit ethidium bromide efflux in a NorA-expressing $S$. aureus strain [84]. A penta-substituted pyridine, 2,6-dimethyl4-phenylpyridine-3, 5-dicarboxylic acid diethyl ester, and proparcine have been isolated from rhizome of Jatropha elliptica. The pyridine was shown to increase the activity of ciprofloxacin and norfloxacin against NorA-expressing $S$. aureus [85]. Active compounds from the cones of Chamaecyparis lawsoniana were screened for resistance-modifying activities and observed that ferruginol and 5-epipisiferol were effective in increasing the efficacy of tetracycline, norfloxacin, erythromycin, and oxacillin against resistant $S$. aureus [86]. Phenolic metabolites from Dalea versicolor (Fabaceae) "mountain delight" were found to inhibit NorA, resulting in the increase of activity of berberine, erythromycin, and tetracycline against $S$. aureus [87]. Piperine, which is a major plant alkaloid within the family Piperaceae, including black pepper (Piper nigrum) and long pepper (Piper longum), has been reported to enhance the accumulation of several antibiotics in $S$. aureus. In Mycobacterium tuberculosis, piperine was shown to inhibit the efflux pump Rv1258c and increase the efficacy of rifampicin. They have also predicted the structure of Rv1258c using bioinformatic tools [88]. Piperine was shown to increase the minimum inhibitory concentration of ethidium bromide and rifampicin in Rv1258c mutants in MDR-TB. Reserpine isolated from Rauwolfia vomitoria was shown to be an inhibitor of efflux pumps in Bacillus subtilis. Isoniazid resistant strains caused by MmpL7 of M. tuberculosis were shown to be reversed into sensitive strains in the presence of reserpine [89]. Berberine, an alkaloid derived from Berberis fremontii and also its derivatives might also be used in combinatorial therapy with other drugs [90]. Farnesol was shown to be a potential efflux pump inhibitor in Mycobacterium smegmatis [91]. Chemical analogues of disulfides of Allium stipitatum were synthesized, which demonstrated efflux pump inhibition and reduction of biofilm formation activity in Mycobacterium tuberculosis [92]. Synergistic action of piperine and Cantharanthus roseus flower extract was also shown to increase the susceptibility of ofloxacin [93]. A plant phenolic compound biochanin A was found to exhibit efflux pump inhibiting activity in Mycobacterium smegmatis [94]. Phenylpropanoids, particularly 1'-S-1'acetoxyeugenol acetate from Alpinia galanga were seen to exhibit efflux pumpinhibiting activity in Mycobacterium smegmatis. Some compounds of Alpinia katsumadai were reported as potential efflux pump inhibitors in Mycobacterium smegmatis [79]. A very recent review has reported the efflux pump inhibitors of non-tuberculous mycobacteria (NTM) 
[95]. Another recent article has reported the role of flavonoids from plant sources, which can act as efflux pump inhibitors in NTM [96]. Due to genomic similarities, these NTM can be used as a model for the evaluation of plant compounds as novel EPIs against Mycobacterium tuberculosis.

Although a large number of compounds have been reported as EPIs in general, very few have been reported to exhibit effectiveness in Mycobacterium tuberculosis. Several plant products have been described which show activity against MDR-TB [97, 98]. However, the role of these compounds as EPIs has not yet been explored. A large number of research studies on the combinations between plant extracts and antibiotics has been focused on the identification and isolation of potential resistance modifiers from plant sources. However, such combinations could also produce antagonistic interactions. Therefore, some studies are considered irrelevant and ignored. Most of these compounds have failed to fulfill certain conditions of clinical relevancy, such as serum concentration, toxicity, immunosuppression, stability, and solubility concerns. For example, verapamil, which is a calcium channel blocker, can act as an efflux pump inhibitor, but it has severe side effects and, therefore, so far, it is not considered safe to be administered in human beings [99]. Piperine is also not used in tuberculosis treatment because of its unknown drug-drug interaction when administered with other drugs [100]. Screening of natural products with an antimycobacterial effect and the further development of drugs is difficult as it is time-consuming, is expensive, and requires sophisticated facilities and animal models. There are several thousand plants as pharmacological targets and most of these compounds exhibit pleiotropic effects by interacting with different targets. Over the years, many plant compounds are being studied for their dual role as efflux pump inhibitors and also as enhancers of macrophage activity which can help in the killing of mycobacteria inside macrophages. But in spite of all these efforts, no efflux pump inhibitors have been clinically approved till now [101, 102].

\section{Role of Computational Methods in Designing Phytocompound-based Drug Against Efflux-Mediated Drug-Resistant Tuberculosis}

The field of computational biology has become increasingly important, particularly in the field of drug designing and discovery. The rapidly increasing molecular biology data has facilitated the computer-based analysis of molecular interactions. There has been substantial progress in this field in the recent years. Interactions between different biomolecules play a fundamental role in all biological processes and are therefore elementary in drug designing. Computer simulation and experimental work go hand in hand for finding molecules that can be used as drugs. Some excellent reviews and articles on the use of computational tools in drug designing can be found in literature [103-106]. One method that plays a pivotal role in drug designing and discovery is molecular docking. It provides an ideal platform for drug discovery based on structural biology [107]. Molecular docking is a method which anticipates the preferred orientation of a small molecule called ligand against a receptor protein called macromolecule or target to make a stable complex [108]. Molecular docking is an excellent tool for screening of plant compounds used as ethnomedicine for TB therapy for their role as efflux pump inhibitors of Mycobacterium tuberculosis [90]. The strategy of molecular docking that can be generally applied in the screening of phytocompounds as EPIs has been discussed below: 
i. The first step in screening is finding the target. There are many putative efflux pumps of Mycobacterium in literature [109]. These can serve as the target against which a number of small molecules will be screened. Firstly, one should check, whether the protein of interest, i.e., the efflux pump structure is present in the Protein Data Bank (PDB) database (https://www.rcsb.org/), which is a database of all experimentally derived protein structures.

ii. If the structure is not found in the PDB database, one can infer the structure of such proteins using homology modeling [100]. Efflux pump proteins are membrane proteins that are difficult to crystallize; hence, there are inherent problems performing X-ray crystallography of these proteins. However, the genome of Mycobacterium tuberculosis has been evaluated, which reveals the presence of various efflux pump genes. Various homology modeling tools are present which can be used to predict the structure from the amino acid sequence of the efflux pump proteins. The sequence of the putative efflux pump proteins can be retrieved from a variety of sequence databases such as Kyoto Encyclopedia of Genes and Genomes (KEGG) (https://www.genome.jp/kegg/) and National Centre for Biotechnology Information (NCBI) (https://www.ncbi.nlm.nih. gov/). Now, the homology modeling tools and softwares will look for close homologues based on its sequence and based on the structure of the homologue, the structure of the protein of interest is constructed. There are various homology modeling softwares which include SWISS MODEL [110], TASSER [111], and Modeller [112].

iii. The modeled structure is now validated by using Prochek or ProSA web servers [113, $114]$.

iv. The modeled structure can be visualized using various visualization softwares like UCSF Chimera [115] and Pymol (https://pymol.org/2/)

v. In this step, the 3D structure of ligands or the phytocompounds used as ethnomedicine can be downloaded from PubChem database (https://pubchem.ncbi.nlm.nih.gov). It is a database of small molecules whose structures are experimentally solved.

vi. Now, one can go for molecular docking of the macromolecule and the ligand. A very common software for molecular docking is AutoDock [116]. Other docking tools are also available like Discovery Studio, PatchDock, MOE-Dock, and GOLD. The macromolecule is prepared for docking by removal of water molecules, if any and stabilizing the charges. The heteroatoms are also removed.

vii. Active sites of the protein target can be predicted by various online tools that are present for active site prediction. Some of these are f-pocket [117] and Gass [118]. This search results in a number of pockets or cavities present in the macromolecule. The best pocket is chosen.

viii. The ligands are initially energy minimized and hydrogens and charges are added to it.

ix. Finally, docking is performed, which utilizes various simulation algorithms like Monte Carlo and distance geometry. Molecular docking results show various conformations of the ligand bound to the target macromolecule with their respective binding energies. The most stable conformation is chosen on the basis of the lowest binding energy.

$\mathrm{x}$. The 3D docked structure where the ligand molecule binds to the target can be visualized in Pymol. The 2D structure can be visualized in the LigPlot program where various bonds like hydrogen bonds and hydrophobic interactions of the ligand and neighboring molecules of the target can be viewed [119]. These two interactions are the most common interactions between proteins and drugs. However, there are also some other 
interactions which might be present like $\pi$-stacking, weak hydrogen bonds, salt bridges, amide stacking, and cation- $\pi$ interactions but in less number [120].

xi. The ligands with the best binding affinity are further filtered by Lipinski's rule of five [121]. This rule states that for a drug to be orally administered, it should possess some properties like the following:

a. It should not possess more than 5 hydrogen bond donors.

b. It should not possess more than 10 hydrogen bond acceptors.

c. It should have a molecular mass of less than 500 daltons.

d. The octanol-water partition coefficient $(\log P)$ should not be more than 5 .

xii. Now, the ADMET (absorption, distribution, metabolism, excretion, and toxicity) property studies of the molecules filtered by the Lipinski's rule of 5 are performed. Several tools are freely available online to explore the chemical property of a compound. This is the most crucial step in designing drug. They help in investigating the variation of drug concentration with time. These tools predicts the in vivo behavior of the models that are predicted on the basis of experimental data. Some of the freely available ADMET softwares are viz. PK Tutor (http://208.73.32.70/tools/tools.htm\#pktutor) and DSSTox (https://www.epa.gov/chemical-research/distributed-structure-searchable-toxicitydsstox-database) and some freely available online ADMET web servers are viz. PreADMET ADMET Prediction (https://preadmet.bmdrc.kr/), Molinspiration (https:// www.molinspiration.com/cgi-bin/properties), PreADMET ADMET Toxicity Prediction (https://preadmet.bmdrc.kr/toxicity/), and many more. The compound that fulfills both the drug likeliness and ADMET criteria can act as a novel and potent EPI.

xiii. Molecular dynamic simulations are used for rationalization of existing data, like interactions with environment like solvent and lipid bilayer and free energy interaction, and validation of structure by homology modeling [122]. One of the most extensively used software for molecular dynamic simulation is GROMACS [123]. This approach of EPI discovery can be expressed in Fig. 1 flow chart.

\section{Some Success Stories Where Computational Biology Was Used in Drug Discovery}

The number of success stories where computational tools are used as a method for drug discovery are rapidly increasing over the years. Few of the interesting examples are discussed here.

i. A plant compound from Ceratostigma willnottianum, a folk medicine, was found to be effective against Helicobacter pylori which causes gastrointestinal problems. But the mechanism of action was unknown. Docking analysis initially revealed that the mechanism of action is against Helicobacter pylori peptidyl transferase (HpPDF). Later when the experimental X-ray crystal structure of apo-HpPDF was revealed, this mechanism of action was verified at the atomic level [124].

ii. Bioinformatic approach involving molecular docking was used to repurpose old drugs for tuberculosis. The target serine/threonine protein kinase, pkn B was targeted for docking 


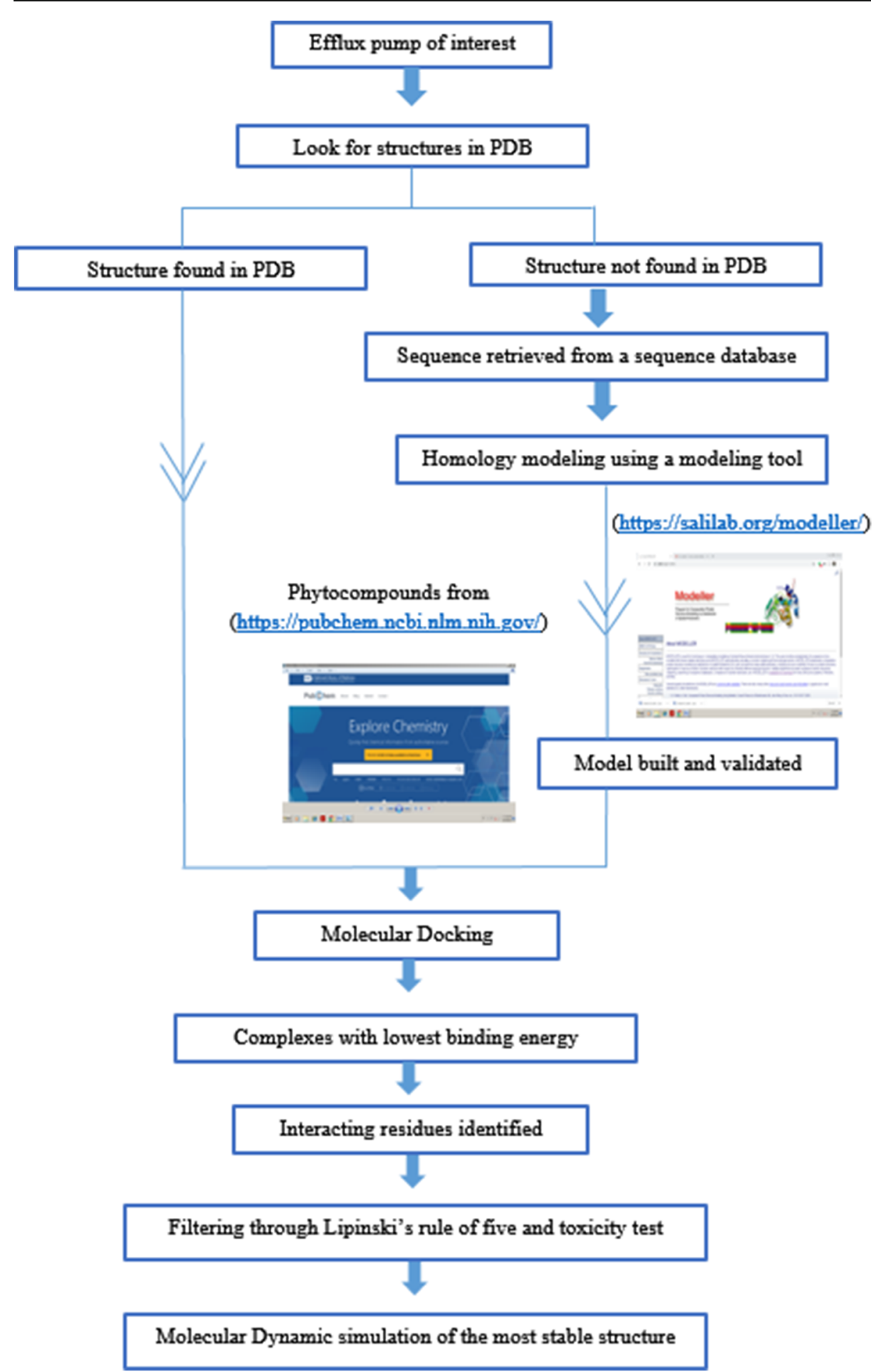

Fig. 1 The computational approach in EPI discovery 
against a number of drugs. Atorvastatin, which was also found to effective against MDRTB by other researches in vitro, was seen to have a strong binding affinity for this protein. Further experimental studies are suggested for this drug along with other strongly bound candidates.

iii. New Delhi metallo- $\beta$-lactamase-1 (NDM-1) is an enzyme that is resistant to all known $\beta$ lactam antibiotics. The thiophene-carboxylic acid was found to be an inhibitor for NDM1. It was found that the sulfur atoms of the ligand might interfere with the zinc ions and water bridge of NDM-1 active site. This finding provides clues for discovery and designing of drugs against NDM-1 [125]

iv. During the severe acute respiratory syndrome (SARS) outbreak in China in 2003, docking analysis was performed by researchers which found Cinanserin as an inhibitor of 3C-like (3CL) protease of SARS. Cinanserin is an old drug and, hence, safe. Therefore, it could be effective against future outbreak of SARS pandemic [126].

v. A set of inhibitors for human cyclophilin A, a key receptor on the immune system, was identified by molecular docking analysis [127].

vi. In a study, a set natural compounds were screened against a RND efflux pump, namely, AdeABC of Acinetobacter baumanii using computational methods and promising results were found and one compound was identified as inhibitor of the pump [128].

\section{Future Scope}

Computational methods are increasingly becoming the methods of choice in drug discovery based on plant products. These methods can prove to be an asset in the field of drug designing, especially in an organism like mycobacteria, which is difficult to handle due to its hazardous nature and the difficulty to culture. Many phytocompound-based studies can be undertaken based on their traditional reports and can easily be screened by these methods. Such an approach will shorten the time and effort in designing drug and EPI. However, after in silico analysis, in vitro and in vivo analysis of the selected compounds are necessary for further validation before administration of the EPIs to human beings.

\section{Conclusion}

"One disease, one target, one drug" approach of drug discovery has been recently challenged mainly due to the complex nature of diseases [129]. An alternative approach to this conventional approach is to develop drugs that target multiple proteins but are essentially safe. Exploitation of plant products is a potential strategy to meet these requirements for designing a drug against MDR-TB. Most of these plants are a part of our diet, and their products have been traditionally used since ages. Plants that are reported to be of use in ethnomedicine and also a large number of phytocompounds whose properties are so far unexplored can be targeted in drug discovery using in silico approaches. These plants can act as efflux pump inhibitors, which in turn can increase the concentration of co-administered drugs. The products which have been traditionally used against tuberculosis can act as leads for drug development as they may act as EPI and drug simultaneously, thereby decreasing side effects and lessening the time of treatment. This could eventually address the problem of hepatic and renal toxicity associated with the drugs now administered for tuberculosis treatment [130]. This may also 
convert the drug-resistant strains into susceptible ones and increase the efficacy of conventional drugs, thereby ameliorating the problem of multidrug resistance.

Author Contribution SSB has reviewed and compiled the paper and conceived and designed the experiments. RBB helped in understanding the bioinformatic tools incorporated in the paper.

VVB helped in understanding the mechanism of antibiotic resistance which helped in the compilation of the manuscript.

JDR helped in reviewing the relevant papers and compilation of paper.

Data Availability There will be data transparency for the present research work.

\section{Declarations}

Ethical Approval This article does not contain any studies with human participants or animals performed by any of the authors. Hence, no formal consent is required.

Consent to Participate All the authors have given the consent to participate in the present research concept.

Consent for Publication All authors have read the final manuscript and gave the consent for publishing the manuscript.

Competing Interests The authors declare no competing interests.

\section{References}

1. Wallgren, A. (1948). The time table of tuberculosis. Tubercle, 29(11), 245-251.

2. Smith, I. (2003). Mycobacterium tuberculosis pathogenesis and molecular determinants of virulence. Clinical Microbiology Reviews, 16(3), 463-496.

3. Peyron, P., Bordier, C., N'Diaye, E. N., \& Maridonneau-Parini, I. (2000). Nonopsonic phagocytosis of Mycobacterium kansasii by human neutrophils depends on cholesterol and is mediated by CR3 associated with glycosylphosphatidylinositol-anchored proteins. J. Immunol., 165(9), 5186-5191.

4. Vergne, I., Chua, J., \& Deretic, V. (2003). Mycobacterium tuberculosis phagosome maturation arrest: selective targeting of PI3P-dependent membrane trafficking. Traffic, 4(9), 600-606.

5. WHO guidelines for treatment of TB 2016. Available from https://www.who.int/publications/guidelines/ tuberculosis/en/. Accessed October 26, 2020

6. Alekshun, M. N., \& Levy, S. B. (2007). Molecular mechanisms of antibacterial multidrug resistance. Cell, 128(6), 1037-1050. https://doi.org/10.1016/j.cell.2007.03.004.

7. Ramaswamy, S., \& Musser, J. M. (1998). Molecular genetic basis of antimicrobial agent resistance in Mycobacterium tuberculosis. Tuberculosis and Lung Diseases, 79, 3-29.

8. Zainuddin, Z. F., \& Dale, J. W. (1990). Does Mycobacterium tuberculosis have plasmids? Tuberle., 71(1), 43-49.

9. Palomino, J. C., \& Martin, A. (2014). Drug resistance mechanisms in Mycobacterium tuberculosis. Antibiotics, 3(3), 317-340. https://doi.org/10.3390/antibiotics3030317.

10. Zhang, Y., \& Yew, W. W. (2015). Mechanisms of drug resistance in Mycobacterim tuberculosis: update 2015. International Journal of Tuberculosis and Lung Diseases., 19(11), 1276-1289(14). https://doi.org/ 10.5588/ijtld.15.0389.

11. Jarlier, V. \& Nikaido, H. (1994). Mycobacterial cell wall: structure and role in natural resistance to antibiotics. FEMS Microbiology Letters, 123(1-2), 11-18.

12. da Silva, P.E. \& Groll, A.V. , Martin, A. \& Palomino, J.C. (2011). Efflux as a mechanism of drug resistance in Mycobacterium tuberculosis. FEMS Immunology and Medical Microbiology,63,1-9.https:// doi.org/10.1111/j.1574-695X.2011.00831.x

13. Mcmurray, L.M., Petrucci, R.E. \& Levy, S.B. (1980). Active efflux of tetracycline encoded by four genetically different tetracycline resistance determinants in Escherichia coli. Proceedings of the National Academy of Sciences, USA ,77, 3974-3977. 
14. Machado, D., Coelho, T.S., Perdigao, J., Pereira, C., Couto, I., Portugal, I., Maschmann, R.D.A., Ramos, D.F., von Groll, A.V., Rossetti, M.L.R., Silva, P.A. \& Viveiros, M (2017). Interplay between mutations and efflux in drug resistant clinical isolates of Mycobacterium tuberculosis. Frontiers in Microbiology, 8 (711), doi: https://doi.org/10.3389/fmicb.2017.00711

15. Kanji, A., Hasan, R., \& Hasan, Z. (2018). Efflux pump as alternate mechanism for drug resistance in Mycobacterium tuberculosis. Indian Journal of Tuberculosis, 66(2019), 20-25.

16. Piddock, L. J. V. (2006). Multidrug-resistance efflux pumps? Not just for resistance. Nature Reviews Microbiology, 4(629-636), 2006.

17. Li, X., \& Nikaido, H. (2009). Efflux mediated drug resistance in bacteria-an update. Drugs, 69(12), 15551623. https://doi.org/10.2165/11317030-000000000-00000.

18. Paulsen, I. T., Chen, J., Nelson, K. E., \& Saier Jr., M. H. (2001). Comparative genomics of microbial drug efflux systems. Journal of Molecular Microbiology and Biotechnology, 3(2), 145-150.

19. Pal, R., Zeeshan, F. \& Hameed, S. (2014). Efflux pumps in drug resistance of Mycobacterium tuberculosis: a panoramic view. International Journal of Current Microbiology and Applied Sciences,3(8), 528546.

20. Dinesh, N, Sharma, S. \& Balganesh, M. (2013). Involvement of efflux pumps in the resistance to peptidoglycan synthesis inhibitors in Mycobacterium tuberculosis. Antimicrobial Agents and Chemotherapy,57, 1941-1943. https://doi.org/10.1128/AAC.01957-12.2013

21. Hao, P., Shi-Liang, Z., Ju, L., Ya-Xin, D., Biao, H., Xu, W., Min-Tao, H., Shou-Gang, K., \& Ke, W. (2011). The role of ABC efflux pump, Rv1456c- Rv1457c-Rv1458c, from Mycobacterium tuberculosis clinical isolates in China. Folia Microbiologica, 56(6), 549-553.

22. Choudhuri, B. S., Bhakta, S., Barik, R., Basu, J., Kundu, M., \& Chakrabarti, P. (2002). Overexpression and functional characterization of an ABC (ATP-binding cassette) transporter encoded by the genes drrA and drrB of Mycobacterium tuberculosis. Biochemical Journal, 367(Pt 1), 279-285. https://doi.org/10. 1042/bj20020615

23. Danilchanka, O., Mailaender, C., \& Niederweis, M. (2008). Identification of a novel multidrug efflux pump of Mycobacterium tuberculosis. Antimicrob Agents and Chemotherapy, 52(7), 25032511.

24. Cole, S. T., Brosch, J., Parkhill, J., et al. (1998). Deciphering the biology of Mycobacterium tuberculosis from the complete genome sequence. Nature., 393(6685), 537-544. https://doi.org/10.1038/31159.

25. Braibant, M., Gilot, P., \& Content, J. (2000). The ATP binding cassette (ABC) transport systems of Mycobacterium tuberculosis. FEMS Microbiology Reviews, 24(4), 449-467. https://oi.org/10.1111/j. 1574-6976.2000.tb00550.x.

26. Gupta, A.K.., Katoch, V.M., Chauhan D.S., Sharma, R.., Singh, M.., Venkatesan, K., Sharma, V.D. (2010). Microarray analysis of efflux pump genes in multidrug-resistant Mycobacterium tuberculosis during stress induced by common anti-tuberculous drugs. Microbial Drug Resistance, 16(1):21-28. doi: https://doi.org/10.1089/mdr.2009.0054.

27. Gopinath, K., Venclovas, C., Ioerger, T. R., Sacchettini, J. C., Mc Kinney, J. D., Mizrahi, V., \& Warner, D. F. (2013). A vitamin $B_{12}$ transporter in Mycobacterium tuberculosis. Open Biology, 3(2), 120175. https://doi.org/10.1098/rsob120175.

28. Calgin, M.K., Sahin, F., Turegun, B., Gerceker, D., Atasever, M., Koksal, D., Karasartova, D. \& Kiyan, M.(2013). Expression analysis of efflux pump genes among drug-susceptible and multidrug resistant Mycobacterium tuberculosis clinical isolates and reference strains. Diagnostic Microbiology and Infectious Disease , 76(3),291-297. doi: https://doi.org/10.1016/j.diagmicrobio.2013.02.033.,2013

29. Louw, G.E., Warren, R.M., Pittius, G., McEvoy, C.R.E., Helden, P.D.V. \& Victor, T.C. (2009). A balancing act: efflux/influx in mycobacterial drug resistance. Antimicrobial agents and chemotherapy, 53(8): 3181-3189. https://doi.org/10.1128/AAC.01577-08

30. Gomez, A., Andreu, N., Ferrer-Nayarro, M., Yero, D., \& Gibert, I. (2016). Triclosan-induced genes Rv1686cRv1687c and Rv3161c are not involved in triclosan resistance in Mycobacterium tuberculosis. Scientific Reports, 6(1), 26221. https://doi.org/10.1038/srep26221.

31. Takiff, H.E., Cimino, M., Musso, M.C., Weisbrod, T., Martinez, R., Delgado, M.B., Salazar, M., Bloom, B.R. \& Jacobs Jr., W.R. (1996). Efflux pump of the proton antiporter family confers low-level fluoroquinolone resistance in Mycobacterium smegmatis. Proceedings of the National Academy of Sciences, 93(1),362-366. https://doi.org/10.1073/pnas.93.1.362

32. Buroni, S., Manina, G., Guglierame, P., Pasca, M. R., Riccardi, G., \& Rossi, E. D. (2006). LfrR is a repressor that regulates expression of the efflux pump LfrA in Mycobacterium smegmatis. Antimicrobial Agents and Chemotherapy, 50(12), 4044 4052. https://doi.org/10.1128/AAC.00656-06.

33. Li, X. Z., Zhang, L., \& Nikaido, H. (2004). Efflux pump mediated intrinsic drug resistance in Mycobacteria smegmatis. Antimicrobial Agents and Chemotherapy, 48(7), 2415-2423. https://doi.org/ 10.1128/AAC.48.7.2415-2423.2004. 
34. Siddiqi, N., Das, R., Pathak, N., Banerjee, S., Ahmed, N., Katoch, V.M. \& Hasnain, S.E. (2004). Mycobacterium tuberculosis isolate with a distinct genomic identity over expresses a Tap like efflux pump. Infection,32 (2): 109 -111.

35. Malinga L.A. (2017). Characterization of efflux pumps genes involved in second-line drug resistance of tuberculosis. $\mathrm{PhD}$ Thesis submitted to University of Pretoria.

36. Nikaido, H., \& Takatsuka, Y. (2009). Mechanisms of RND multidrug efflux pump. Biochimica et Biophysica Acta (BBA) - Proteins and Proteomics, 1794(5), 769-781.

37. Domenech, P., Reed, M. B., \& Barry, C. E. (2005). Contribution of the Mycobacterium tuberculosis MmpL protein family to virulence and drug resistance. Infection and Immuity., 73(6), 3492-3501. https:// doi.org/10.1128/IAI.73.6.3492-3501.2005.

38. Hoagland, D. T., Liu, J., Lee, R. B., \& Lee, R. E. (2016). New agents for the treatment of drug-resistant Mycobacterium tuberculosis. Advanced Drug Delivery Reviews, 102, 55-72. https://doi.org/10.1016/j. addr.2016.04.026.

39. Pasca, M.R., Guglierame, P., Rossi, E.D., Zara, F., Riccardi, G. (2005). mmpL7 gene of Mycobacterium tuberculosis is responsible for isoniazid efflux in Mycobacterium smegmatis. Antimicrobial Agents and Chemotherapy,49(11):4775-4777. https://doi.org/10.1128/AAC.49.11.4775-4777.2005

40. Hartkoorn, R. C., Uplekar, S., \& Cole, S. T. (2014). Cross-resistance between clofazimine and bedaquiline through upregulation of MmpL5 in Mycobacterium tuberculosis. Antimicrobial Agents and Chemotherapy, 58(5), 2979-2981. https://doi.org/10.1128/AAC.00037-14.

41. Black, P. A., Warren, R. M., Louw, G. E., van Helden, P. D., Victor, T. C., \& Kana, B. D. (2014). Energy metabolism and drug efflux in Mycobacterium tuberculosis. Antimicrobial Agents and Chemotherapy, 58(5), 2491-2503. https://doi.org/10.1128/AAC.02293-13.

42. Yerushalmi, H., Lebendiker, M., \& Schuldiner, S. (1995). Emr E, an Escherichia coli multi drug transporter exchanges toxic cations and $\mathrm{H}^{+}$and is soluble in organic solvents. The Journal of Biological chemistry, 270(12), 6856-6863.

43. Srinivasan, V.B., Rajamohan, G. \& Gebreyes, W.A. (2009) Role of AbeS, a novel efflux pump of the SMR family of transporters in resistance to antimicrobial agents. Antimicrobial Agents and Chemotherapy, 53(12), 5312-5316.doi: https://doi.org/10.1128/AAC.00748-09

44. De Rossi, E., Branzoni, M., Cantoni, R., Milanno, A., Riccardi, G. \& Ciferri, O.(1998). mmr, a Mycobacterium tuberculosis gene conferring resistance to small cationic dyes and inhibitors. Journal of Bacteriology, 180(22), 6068-6071. https://doi.org/10.1128/JB.180.22.6068-6071.1998

45. Paulsen, I.T., Skurray, R.A., Tam, R., Saier Jr, M.H., Turner, R. J., Weiner, J.H., Goldberg, E.B. \& Grinius, L.L.(1996). The SMR family: a novel family of multidrug efflux proteins involved with the efflux of lipophilic drugs. Molecular Microbiology,19(6), 1167-1175. https://doi.org/10.1111/j.1365-2958.1996. tb02462.x

46. Brown, M. H., Paulsen, I. T., \& Skurray, R. A. (1999). The multidrug efflux protein NorM is a prototype of a new family of transporters. Molecular Microbiology, 31(1), 394-395. https://doi.org/10.1046/j.13652958.1999.01162.x.

47. Ogawa, W., Minato, Y., Dodan, H., Onishi, M., Tsuchiya, T. \& Kurodo, T. (2015). Characterization of MATE-type multidrug efflux pumps from Klebsiella pneumonia MGH78578. PLoS One,10(3):e0121619. doi: https://doi.org/10.1371/journal.pone.0121619,2015

48. Garima, K., Pathak, R., Tandon, R., Rathor, N., Sinha, R., Bose, M., \& Verma-Basil, M. (2015). Differential expression of efflux pump genes of Mycobacterium tuberculosis in response to varied subinhibitory concentrations of antituberculosis agents. Tuberculosis, 95(2), 155-161. https://doi.org/10. 1016/j.tube.2015.01.005.

49. Liu, J., Wanliang, S., Zhang, S., Hao, X., Maslov, D.A., Shur, K.V., Bekker, O.B., Danilenko, V.N. \& Zhang, Y. (2019). Mutations in efflux pump Rv1258c (Tap) cause resistance to pyrazinamide, isoniazid, and streptomycin in M. tuberculosis. Frontiers in Microbiology,10:216. https://doi.org/10.3389/fmicb. 2019.00216

50. Kanji, A., Hasan, R., Ali, A., Zaver, A., Zhang, Y., Imtiaz, K., Shi, W., Clark, T. G., McNurney, R., Phelan, J., Rao, S., Shafiq, S., \& Hasan, Z. (2017). Single nucleotide polymorphisms in efflux pumps genes in extensively drug resistant Mycobacterium tuberculosis isolates from Pakistan. Tuberculosis, 107, 20-30. https://doi.org/10.1016/j.tube.2017.07.012.

51. Martin, P. S., \& Sharrock, F. W. (1964). Pollen analysis of prehistoric human feces: a new approach to ethnobotany. American Antiquity, 30(2), 168-180 https://www.jstor.org/stable/278848.

52. Kole, P.L., Jadhav, H.R., Thakurdesai, P \& Nagappa, A.N. (2005). Cosmetic potential of herbal extracts. Indian Journal of Natural Products and Resources,4(4), 315-321

53. Atharva Vedic views in tuberculosis. (1988). Anc Sci Life, 8(2), I.

54. Prasad, P. V. V. (2002). General medicine in Atharvaveda with special reference to Yaksma (consumption/ tuberculosis). Bulletin of the Indian Institute of History of Medicine. 32(1), 1-14 
55. Muniyan, R., \& Gurunathan, J. (2016). Lauric acid and myristic acid from Allium sativum inhibit the growth of Mycobacterium tuberculosis $\mathrm{H} 37 \mathrm{Ra}$ : in silico analysis reveals possible binding to protein kinase B. Pharmaceutical Biology, 54(12), 2814-2821.

56. Tawde, K. V., Gacche, R. N., \& Pund, M. M. (2011). Evaluation of selected Indian traditional medicinal plants against Mycobacterium tuberculosis with antioxidant and cytotoxicity study. Asian Pacific Journal of Tropical disease, 2(2), S685-S691.

57. Perme, N., Choudhury, S. N., Choudhury, R., Natung, T., De, B. (2015). Medicinal plants in traditional use at Arunachal Pradesh, India. International Journal of Phytopharmacy,5(5), 86-98.

58. Khongsai, M., Saikia, S. P., \& Kayang, H. (2011). Ethnomedicinal plants used by different tribes of Arunachal Pradesh. Indian Journal of Traditional Knowledge., 10(3), 541-546.

59. Sajem, A. L. \& Gosai, K. (2010) Ethnobotanical investigations among the Lushai tribes in North Cachar Hills district of Assam, Northeast India. Indian Journal of Traditional Knowlwdge,9(1), 108-113.

60. Kutum, A., Sharma, R., \& Hazarika, D. (2011). An ethnobotanical study of Mishing tribe living in fringe villages of Kaziranga National Park of Assam, India. Indian Journal of Fundamental and Applied Life Sciences., 1(4), 45-61.

61. Khiangte, Z., \& Lalramnghinglova, H. (2017). An ethno botanical study of Ralte communities in the north eastern part of Mizoram, North East India. Journal of Natural Products and PlantResources, 7(4), 1-10.

62. Dash, P. K., Sahoo, S., \& Bal, S. (2008). Ethnobotanical studies on orchids of Niyamgiri Hill Ranges, Orissa, India. Ethnobotanical Leaflets, 12, 70-78.

63. Liu, Q. F., \& Zhao, W. M. (2003). A new dedonbrine type alkaloid from Dendrobium nobile. Chinese Chemical Letters, 14, 278-279.

64. Sulitha, S., Devi, S. K., Gunasekaran, K., Carehome, P. H., Bhattacharjee, A., \& Velmurugan, D. (2015). Phytochemical analyses and activity of herbal medicinal plants of North-East India for anti-diabetic, anticancer and anti-tuberculosis and their docking studies. Current Topics in Medicinal Chemistry, 15, 21-36.

65. Panda, A.K. (2012). Medicinal plants use and primary health care in Sikkim. International Journal of Ayurvedic and Herbal Medicine 2(2), 253:259.

66. Das, T., Mishra, S. B., Saha, D., \& Agarwal, S. (2012). Ethnobotanical survey of medicinal plants used by ethnic and rural people in Eastern Sikkim Himalayan Region. African Journal of Basic \& Applied Sciences, 4(1), 16-20.

67. Rai, R. (2016). Herbal remedies in cure of tuberculosis prevalent among ethnic communities in central India. Tropical Plant Research, 3(2), 344-353.

68. Raj, A.J., Biswakarma, S., Pala, N.A., Shukla, G., Vineeta, Kumar, M., Chakravarty, S. \& Bussmann, W. (2018). Indigenous uses of ethnomedicinal plants among forest-dependent communities of Northern Bengal, India. Journal of Ethnobiology and Ethnomedicine, 14(8), https://doi.org/10.1186/s13002-0180208-9, 8

69. Pendleton, J. N., Gormin, S. P., \& Gilmore, B. F. (2014). Clinical relevance of ESKAPE pathogens. Expert review of anti-infective therapy, 11(3), 297-308. https://doi.org/10.1586/eri.13.12.

70. Vakil, N., Hahn, B. \& Mc Sorley, D. (1997). Clarithromycin-resistant Helicobacter pylori in patients with duodenal ulcer in the United States. The American Journal of Gastroenterology, 93(9): 1432-1435. https:// doi.org/10.1111/j.1572-0241.1998.455_t.x

71. Deguchi, T, Nakane, K., Yasuda, M. \& Maeda, S. (2014) Emergence and spread of drug resistant Neisseria gonorrhoeae. The Journal of Urology, 184(3), 851-858. https://doi.org/10.1016/j.juro.2010.04. 078

72. Van Etten, H. D., Mansfield, J. W., Bailey, J. A., \& Farmer, E. E. (1994). Two classes of plant antibodies: phytoalexins vs "phytoanticipins". The Plant Cell, 6(9), 1191-1192. https://doi.org/10.1105/tpc.6.9.1191.

73. Tegos, G., Stermitz, F.R., Lomovskaya, O. \& Lewis, K. (2002). Multidrug pump inhibitors uncover remarkable activity of plant antimicrobials. Antimicrobial Agents andChemotherapy ,46(10), 3133-3141. DOI: https://doi.org/10.1128/AAC.46.10.3133-3141.

74. Chan B.C., Ip M., Lau C.B.S., Lui, S.L., Jolivalt, C., Ganem-Elbez, C., Litaudon, M., Reiner, N. E., Gong, H., See, R. H., Fung, K.P. and Leung, P.C. (2011). Synergistic effects of baicalein with ciprofloxacin against NorA over-expressed methicillin-resistant Staphylococcus aureus (MRSA) and inhibition of MRSA pyruvate kinase. Journal of Ethnopharmacology, 137, 767-73.https://doi.org/10.1016/j.jep. 2011.06.039

75. Foroughi, A., Pournaghi, P., Zhaleh, M., Zangeneh, A., Zangeneh, M. M., \& Moradi, R. (2016). Antibacterial activity and phytochemical screening of essential oil of Foeniculum vulgare. International Journal of Pharmaceutical and Clinical Research, 8(11), 1505-1509.

76. Ahmed, I., Mehmood, Z. \& Mohammad, F. (1998). Screening of some Indian medicinal plants for their antimicrobial properties. Journal of Ethnopharmacology 62,183-193. https://doi.org/10.1016/S03788741(98)00055-5 
77. Lomovskaya, O. \& Bostian, K.A. (2006). Practical applications and feasibility of efflux pump inhibitors in the clinic - a vision for applied use. Biochemical Pharmacology ,71(7),910-918.

78. Kaatz, G. W. (2005). Inhibition of bacterial efflux pumps: a new strategy to combat increasing antimicrobial agent resistance. Expert Opinion on Emerging Drugs, 7(2), 223-233. https://doi.org/10.1517/ 14728214.7.2.223.

79. Prasch, S., \& Bucar, F. (2015). Plant derived inhibitors of bacterial efflux pumps: an update. Phytochemistry Reviews, 14(6), 961-974.

80. Hanna, Y. M., Shirin, J., Sutton, M. J., \& Khondaker, M. R. (2016). Current advances in developing inhibitors of bacterial multi drug efflux pumps. Current Medicinal Chemistry, 23, 1062-1081.

81. Padyana, S. R. M., Dipin, K. M., Nayak, B. B., \& Varela, M. F. (2018). Antimicrobial compounds of plant origin as efflux pump inhibitors: new avenues for controlling multidrug resistant pathogens. Journal of Antimicrobial agents, 4(1), 1-6. https://doi.org/10.4172/2472-1212.1000159.

82. Yam, T.S., Hamilton-Miller, J.M. \& Shah, S. (1998). The effect of a component of tea (Camellia sinensis) on methicillin resistance, PBP2' synthesis, and beta-lactamase production in Staphylococcus aureus. Journal of Antimicrobial Chemotherapy ,42(2), 211-216. https://doi.org/ 10.1093/jac/42.2.211

83. Kondo, K., Takaishi, Y., Shibata, H. \& Higuti, T. (2006). ILSMRs (intensifier of beta-lactam-susceptibility in methicillin-resistant Staphylococcus aureus) from tara [Caesalpinia spinosa (Molina) Kuntze]. Phytomedicine,13(3), 209-212. https://doi.org/10.1016/j.phymed.2004.08.001

84. Oluwatuyi, M., Kaatz, W. \& Gibbons, S. (2004). Antibacterial and resistance modifying activity of Rosmarinus officinalis. Phytochemistry, 65(24):3249-3254.https://doi.org/10.1016/j.phytochem.2004.10. 009

85. Marquez, B., Neuville, L., Moreau, N. J., Genet, J., dos Santos, A. F., Andrade, N. C. C., \& SantAna, A. E. G. (2005). Multidrug resistance reversal agent from Jatropha elliptica. Phytochemistry, 66(15), 1804 1811. https://doi.org/10.1016/j.phytochem.2005.06.008.

86. Smith, E. C., Williamson, E. M., Wareham, N., Kaatz, G. W., \& Gibbons, S. (2007). Antibacterials and modulators of bacterial resistance from the immature cones of Chamaecyparis lawsoniana. Phytochemistry, 68(2), 210-221. https://doi.org/10.1016/j.phytochem.2006.10.001.

87. Belofsky, G., Percivill, D., Lewis, K., Tegos, G. P., \& Ekart, J. (2004). Phenolic metabolites of Dalea versicolor that enhance antibiotic activity against model pathogenic bacteria. Journal of Natural Products, 67(3), 481-484. https://doi.org/10.1021/np030409c.

88. Sharma, S., Kumar, M., Sharma, S., Nargotra, A., Koul, S., \& Khan, I. A. (2010). Piperine as an inhibitor of Rv1258c, a putative multidrug efflux pump of Mycobacterium tuberculosis. Journal of Antimicrobial Chemotherapy, 65(8), 1694-1701. https://doi.org/10.1093/jac/dkq186.

89. Stavri, M., Piddock, L. J. V., \& Gibbons, S. (2007). Bacterial efflux pump inhibitors from natural sources.Journal of. Antimicrobial Chemotherapy, 59(6), 1247-1260. https://doi.org/10.1093/jac/ dk1460.

90. Kapp, E., Malan, S., Joubert, J., \& Sampson, S. L. (2018). Small molecule efflux pump inhibitor in Mycobacterium tuberculosis: a rational drug design perspective. Mini-Reviews in Medicinal Chemistry, 18(1), 72-86. https://doi.org/10.2174/1389557517666170510105506.

91. Jin, J., Zhang, J., Guo, N., Sheng, H., Li, L., Liang, J., Wang, X., Li, Y., Liu, M., Wu, X., \& Yu, L. (2010). Farnesol, a potential efflux pump inhibitor in Mycobacterium smegmatis. Molecules, 15(11), 7750-7762. https://doi.org/10.3390/molecules15117750.

92. Danquah, C. A., Kakagianni, E., Khondkar, P., Maitra, A., Rahman, M., Evangelopoulos, D., McHugh, T. D., Stapleton, P., Malkinson, J., Bhakta, S., \& Gibbons, S. (2018). Analogues of disulphides from Allium stipitatum demonstrate potent anti-tubercular activities through drug efflux pump and biofilm inhibition. Scientific Reports, 1150 .

93. Raja, A., Abdul, K. M., et al. (2015). In vitro studies on efflux pump inhibition of Catharanthus roseus and piperine against ofloxacin resistant M. tuberculosis. International Journal of Pharmaceutical Science Invention, 4(9), 2319-6718.

94. Lechner, D., Gibbons, S., \& Bucar, F. (2008). Plant phenolic compounds as ethidium bromide efflux inhibitors in Mycobacterium smegmatis. Journal of Antimicrobial Chemotherapy, 62(2), 345-348.

95. Rindi, L. (2020). Efflux pump inhibitors against non tuberculous mycobacteria. International Journal of Molecular Sciences, 21(12), 4191. https://doi.org/10.3390/ijms21124191.

96. Solnier, J., Martin, L., Bhakta, S., \& Bucar, F. (2020). Flavonoids as novel efflux pump inhibitors and antimicrobials against both environmental and pathogenic intracellular mycobacterial species. Molecules, 25(3), 734. https://doi.org/10.3390/molecules25030734.

97. Pandit, R., Singh, P. K., \& Kumar, V. (2015). Natural remedies against multi-drug resistant Mycobacterium tuberculosis. Journal of Tuberculosis Research, 3(04), 171-183. 
98. Shin, J., Prabhakaran, V.S. \& Kim, K. (2018). The multi-faceted potential of plant-derived metabolites as antimicrobial agents against multidrug-resistant pathogens. Microbial Pathogenesis, 116, 209-214.https:// doi.org/10.1016/j.micpath.2018.01.043

99. Pule, C.P., Sampson, S.L, Warren, R.M., Black, P.A., van Helden, P.D., Victor, T.C. \& Louw, G.E. (2015). Efflux pump inhibitors: targeting mycobacterial efflux pumps to enhance TB therapy. Journal of Antimicrobial Chemotherapy, 71(1), 17-26, https://doi.org/10.1093/jac/dkv316.

100. Cloete, R., Kapp, E., Joubert, J., Christoffels, A., \& Malan, S. F. (2018). Molecular modeling and simulation studies of the Mycobacterium tuberculosis multi drug efflux pump protein Rv1258c. PLoS ONE, 13(11), e0207605. https://doi.org/10.1371/journal.pone.0207605.

101. Viveiros, M., Martins, M., Rodrigues, L., Machado, D., Couto, I., Ainsa, J. \& Amarel, L. (2014). Inhibitors of mycobacterial efflux pumps as potential boosters for antitubercular drugs. Expert Review of AntiInfective Therapy, 10(9), 983-998.https://doi.org/10.1586/eri.12.89

102. Sharma, A., Gupta, V. K., \& Pathania, R. (2019). Efflux pump inhibitors for bacterial pathogens: from bench to bedside. The Indian Journal of Medical Research, 149(2), 129-145. https://doi.org/10.4103/ijmr. IJMR 207917.

103. Zheng, M., Liu, X., Xu, Y., Li, H., Luo, C., \& Jiang, H. (2013). Computational methods for drug design and discovery. Trends in Pharmacological Sciences, 34(10), 549-559. https://doi.org/10.1016/j.tips.2013. 08.004.

104. Xia, X. (2017). Bioinformatics and drug discovery. Current topics in Medicinal Chemistry, 17(15), 17091726. https://doi.org/10.2174/1568026617666161116143440.

105. Jha, D. K., Panda, L., Lavanya, P., Ramaiah, S., \& Anbrasu, A. (2012). Detection and confirmation of alkaloids in leaves of Justicia adhatoda and bioinformatics approach to elicit its anti-tuberculosis activity. Applied Biochemistry and Biotechnology, 168(5), 980-990. https://doi.org/10.1007/s12010-012-9834-1.

106. Pulaganti, M., Banaganapalli, B., Mulakayala, C., Chitta, S. K., \& Anuradha, C. M. (2014). Molecular modeling and docking studies of O-succinylbenzoate of $\mathrm{M}$. tuberculosis - a potential drug target for antituberculosis drug design. Applied Biochemistry and Biotechnology, 172(3), 1407-1432.

107. Ferreira, L. G., Santos, R. N. D., Oliva, G., \& Andricopulo, A. D. (2015). Molecular docking and structure-based drug design strategies. Molecules, 20(7), 13384-13421. https://doi.org/10.3390/ molecules200713384.

108. Lengauer, T. \& Rarey M. (1996). Computational methods for bimolecular docking. Current Opinion in Structural Biology, 6, 402-406.https://doi.org/10.1016/S0959-440X(96)80061-3

109. Viveiros, M., Leandro, C. \& Amaral, L. (2003). Mycobacterial efflux pumps and chemotherapeutic implications. International Journal of Antimicrobial Agents, 22:274-278.https://doi.org/10.1016/S09248579(03)00208-5

110. Biasini, M, Bienert, S., Waterhouse, A., Arnold, K., Studer, G., Schmidt, T., Kiefer, F., Cassarino, T.G., Bertoni, M., Bordoli, L. \& Schwede, T. (2014). SWISS-MODEL: modelling protein tertiary and quaternary structure using evolutionary information. Nucleic Acids Research , 42, W252-258.https://doi.org/10. 1093/nar/gku340

111. Zhang, Y., Arakaki, A.K. \&Skolnick, J. (2005). TASSER: an automated method for the prediction of protein tertiary structures in CASP6.Proteins, 61 (7), 91-98. https://doi.org/10.1002/prot.20724

112. Eswar, N., Webb, B., Marti-Renom, M.A., Madhusudhan, M.A., Eramian, D., Shen, M., Pieper, U. \& Sali, A. (2006). Comparative protein structure modeling using modeller. Current Protocols in Bioinformatics, 0 5:,Unit-5.6. doi:https://doi.org/10.1002/0471250953.bi0506s15.

113. Laskowski,R.A., MacArthur, M. W., Moss, D. S. \& Thornton, J. M. (1993). PROCHECK: a program to check the stereochemical quality of protein structures. Journal of Applied Crystallography, 26,283-291. https://doi.org/10.1107/S0021889892009944, 2

114. Wiederstein, M. \& Sippl, M.J. (2007). ProSA-web: interactive web service for the recognition of errors in three-dimensional structures of proteins. Nucleic Acids Research, 35, Web Server issue: W407-W410. https://doi.org/10.1093/nar/gkm290, 2007

115. Pettersen, E. F., Goddard, T. D., Huang, C. C., Couch, G. S., Greenblatt, D. M., Meng, E. C., \& Ferrin, T. E. (2004). UCSF Chimera-a visualization system for exploratory research and analysis. Journal of Computational Chemistry, 25(13), 1605-1612. https://doi.org/10.1002/jcc.20084.

116. Morris, G. M., Huey, R., Lindstrom, W., Sanner, M. F., Belew, R. K., Goodsell, D. S., \& Olson, A. J. (2009). Autodock4 and AutoDockTools4: automated docking with selective receptor flexibility. Journal of Computational Chemistry, 30(16), 2785-2791. https://doi.org/10.1002/jcc.21256.

117. Guilloux, V. L., Schmidtke, P., \& Tuffery, P. (2009). Fpocket: an open source platform for ligand pocket detection. BMC Bioinformatics, 10(1), 168. https://doi.org/10.1186/1471-2105-10-168.

118. Izidoro, S. C., de Melo-Minardi, R. C., \& Pappa, G. L. (2015). GASS: identifying enzyme active sites with genetic algorithms. Bioinformatics, 31(6), 864-870. https://doi.org/10.1093/ bioinformatics/btu746. 
119. Wallace, A. C., Laskowski, R. A., \& Thornton, J. M. (1995). LIGPLOT: a program to generate schematic diagrams of protein-ligand interactions. Protein Engineering, Design and Selection, 8(2), 127-134. https:// doi.org/10.1093/protein/8.2.127.

120. De Freitas, R. F., \& Schapira, M. (2017). A systematic analysis of atomic protein-ligand interactions in the PDB. Medicinal Chemistry Communications, 8(10), 1970-1981. https://doi.org/10.1039/C7MD00381A.

121. Lipinski, C.A. (2004). Lead- and drug-like compounds: the rule-of-five revolution. Drug discovery today: Technologies ,1(4): 337-341. https://doi.org/10.1016/j.ddtec.2004.11.007

122. Ramaswamy, V. K., Cacciotto, P., Malloci, G., Vargiu, A. V., \& Ruggerone, P. (2017). Computational modelling of efflux pumps and their inhibitors. Essays in Biochemistry, 61(1), 141-156. https://doi.org/10. 1042/EBC20160065.

123. Berendsen, H. J. C., Spoel, D. V., \& van Drunen, R. (1995). GROMACS: a message-passing parallel molecular dynamics implementation. Computer Physics Communications, 91(1-3), 43-56.

124. Cai, J. H., Han, C., Hu, T., Zhang, J., Wu, D., Wang, F., Liu, Y., Ding, J., Chen, K., Yue, J., Shen, X., \& Jiang, H. (2006). Peptide deformylase is a potential target for anti-Helicobacter pylori drugs: reverse docking, enzymatic assay, and X-ray crystallography validation. Protein Science, 15(9), 2071-2081. https://doi.org/10.1110/ps.062238406.

125. Shen, B., Yu, Y., Cao, X., Lao, X., Fang, Y., Shi, Y., Chen, J., \& Zhang, H. (2013). Inhibitor discovery of full-length New Delhi metallo-b-lactamase-1 (NDM-1). PLoS ONE, 8(5), e62955.

126. Chen, L. L., Gui, C., Luo, X., Yang, Q., Gunther, S., Scandella, E., Drosten, C., Bai, D., He, X., Ludewig, B., Chen, J., Luo, H., Yang, Y., Yang, Y., Zou, J., Thiel, V., Chen, K., Shen, J., Shen, X., \& Jiang, H. (2005). Cinanserin is an inhibitor of the 3C-like proteinase of severe acute respiratory syndrome coronavirus and strongly reduces virus replication in vitro. Journal of Virology, 79(11), 7095-7103. https://doi. org/10.1128/JVI.79.11.7095-7103.2005.

127. Li, J., Zhang, J., Chen, J., Luo, X., Zhu, W., Shen, J., Liu, H., Shen, X., \& Jiang, H. (2006). Strategy for discovering chemical inhibitors of human cyclophilin A: focused library design, virtual screening, chemical synthesis and bioassay. Journal of Combinatorial Chemistry, 8(3), 326-337. https://doi.org/10. $1021 / \operatorname{cc} 0501561$.

128. Verma, P., \& Tiwari, T. (2018). Targeting outer membrane protein component AdeC for the discovery of efflux pump inhibitor against AdeABC efflux pump of multidrug resistant Acinetobacter baumannii. Cell Biochemistry and Biophysics, 76(3), 391-400. https://doi.org/10.1007/s12013-018-0846-5.

129. Wermuth, C.G. (2004) Multitargeted drugs: the end of the "one-target-one-disease" philosophy? Drug Discovery Today,9(19):826-827.doi: https://doi.org/10.1016/S1359-6446(04)03213-1.

130. Brindha, S., Vincent, S., Velmurugan, D., Ananthakrishnan, D., Sundaramurthi, J. C., \& Gnanadoss, J. J. (2017). Bioinformatics approach to prioritize known drugs towards repurposing for tuberculosis. Medical Hypotheses, 103, 39-45.

Publisher's Note Springer Nature remains neutral with regard to jurisdictional claims in published maps and institutional affiliations. 